\title{
Immunosuppressive strategies in lung transplantation
}

\author{
Paul A. Chung, Daniel F. Dilling \\ Division of Pulmonary and Critical Care, Loyola University Chicago, Stritch School of Medicine, Maywood, IL, USA \\ Contributions: (I) Conception and design: All authors; (II) Administrative support: None; (III) Provision of study materials or patients: None; (IV) \\ Collection and assembly of data: None; (V) Data analysis and interpretation: None; (VI) Manuscript writing: All authors; (VII) Final approval of \\ manuscript: All authors. \\ Correspondence to: Daniel F. Dilling, MD. Division of Pulmonary and Critical Care, Loyola University Chicago, Stritch School of Medicine, 2160 S \\ 1st Ave, Maywood, IL 60153, USA. Email: ddillin@lumc.edu.
}

\begin{abstract}
Lung transplantation is a viable option for those with end-stage lung disease which is evidenced by the continued increase in the number of lung transplantations worldwide. However, patients and clinicians are constantly faced with acute and chronic rejection, infectious complications, drug toxicities, and malignancies throughout the lifetime of the lung transplant recipient. Conventional maintenance immunosuppression therapy consisting of a calcineurin inhibitor (CNI), anti-metabolite, and corticosteroids have become the standard regimen but newer agents and modalities continue to be developed. Here we will review induction agents, maintenance immunosuppressives, adjunctive therapies and other strategies to improve long-term outcomes.
\end{abstract}

Keywords: Lung transplantation; induction; maintenance; review

Submitted Aug 31, 2019. Accepted for publication Nov 18, 2019.

doi: 10.21037/atm.2019.12.117

View this article at: http://dx.doi.org/10.21037/atm.2019.12.117

\section{Introduction}

Since the first human lung transplant in 1963 (1), nearly 65,000 lung transplantations have been reported worldwide (2). Unfortunately, median survival remains the lowest of the solid organ transplants at 6.5 years (2). The main challenges to long-term survival are acute and chronic rejection, infectious complications, drug toxicities, and malignancies. Although conventional maintenance immunosuppression therapy consisting of a calcineurin inhibitor (CNI), anti-metabolite, and corticosteroids remains the dominant drug regimen for lung transplantation, immunosuppressive strategies continue to evolve to address these challenges. We will review the current available immunosuppressive medications, the data behind their use, and some of the adjunctive therapies and clinical tools that are being developed to improve long-term outcomes. In this review, the term chronic lung allograft dysfunction (CLAD) as described by a consensus definition from the pulmonary council of the International Society of Heart and Lung Transplantation (ISHLT) (3) including its subtypes, bronchiolitis obliterans syndrome (BOS) and restrictive allograft syndrome (RAS), has been used in place of the historical term BOS unless specified by the study.

\section{Induction immunosuppression}

Induction therapy utilizes intensive immunosuppression in the perioperative and/or the immediate post-operative period to reduce the risk of T-cell mediated early rejection. Induction agents primarily target T-cells and cause depletion and/or interruption of their activation and proliferation. According to the most recent International Society for Heart and Lung Transplantation (ISHLT) registry data, the proportion of patients receiving induction immunosuppression has increased over the last decade with $76 \%$ of adult lung transplant recipients receiving any induction agent in 2016 (2). The three commonly used induction agents are basiliximab, anti-thymocyte globulin (ATG) and alemtuzumab (Table 1). Two other induction agents that had previously been used are now no longer available due to manufacturers voluntary withdrawal 
Table 1 Induction agents for lung transplantation

\begin{tabular}{|c|c|c|c|}
\hline Induction agent & Mechanism & Adverse effects & Additional notes \\
\hline
\end{tabular}

(daclizumab and muromonab-CD3).

Basiliximab (Simulect ${ }^{\circledR}$ ) is a monoclonal antibody that is selectively directed against the interleukin-2 (IL-2) receptor alpha-chain, specifically binding to the CD25 antigen on activated T-lymphocytes thereby preventing binding of IL-2, a signal for T-cell proliferation, which results in a decrease in circulating T-cells without depletion (4). Rabbit ATG (rATG, Thymoglobulin ${ }^{\circledR}$ ) is a purified, pasteurized, immunoglobulin $\mathrm{G}$ obtained by immunization of rabbits with human thymocytes whereas equine or horse ATG (eATG, Atgam ${ }^{\circledR}$ ) is a purified, concentrated, and sterile gamma globulin, primarily monomeric IgG, from hyperimmune serum of horses immunized with human thymus lymphocytes. ATG depletes T-cells from circulation and modulates T-cell activation, homing, and cytotoxic activities $(5,6)$. Alemtuzumab $\left(\right.$ Campth $\left.^{\circledR}\right)$ is a recombinant DNA-derived humanized monoclonal antibody that is directed against CD52, a surface glycoprotein expressed on T- and B-lymphocytes, NK cells, monocytes, and macrophages causing antibodydependent lysis of cells (7), leading to prolonged T- and B-cell depletion. Consistent with previous registry data, the use of IL-2 receptor antagonists continues to increase as the use of anti-lymphocyte/ATG declines; the use of alemtuzumab has been variable throughout the last decade with a modest decline since 2014 (2) (Figure 1).

The rationale for induction immunosuppression in lung transplantation is based on outcomes from previous studies in other solid organ transplantation. To date, studies of induction immunosuppression in lung transplantation have been either small or retrospective in nature and although there are conflicting results, there are trends suggesting that induction agents decrease the incidence of acute rejection and provide improvements in long-term outcomes without a significant increase in infectious complications or adverse side effects (9-23). The most convincing data showing benefits of induction immunosuppression come from two large, retrospective studies using the ISHLT and United Network for Organ Sharing (UNOS) registry databases. Hachem et al. (10) found that among 3,970 adult single and bilateral lung transplant recipients, the use of an IL-2 receptor antagonist was associated with lower incidence of acute rejection $(15 \%$ vs. $22 \%, \mathrm{P}<0.0005)$ and a higher graft survival rate at 4 years $(64 \%$ vs. $57 \%, \log$ rank $\mathrm{P}=0.0067)$ compared to no induction immunosuppression. Importantly, there was a 4-year survival advantage in both single and bilateral lung transplant recipients receiving an IL-2 receptor antagonist versus no induction [relative risk (RR) $=0.82 ; 95 \%$ confidence interval $(\mathrm{CI}): 0.71-0.95, \mathrm{P}=0.007]$ independent of other risk factors. Induction with ATG 


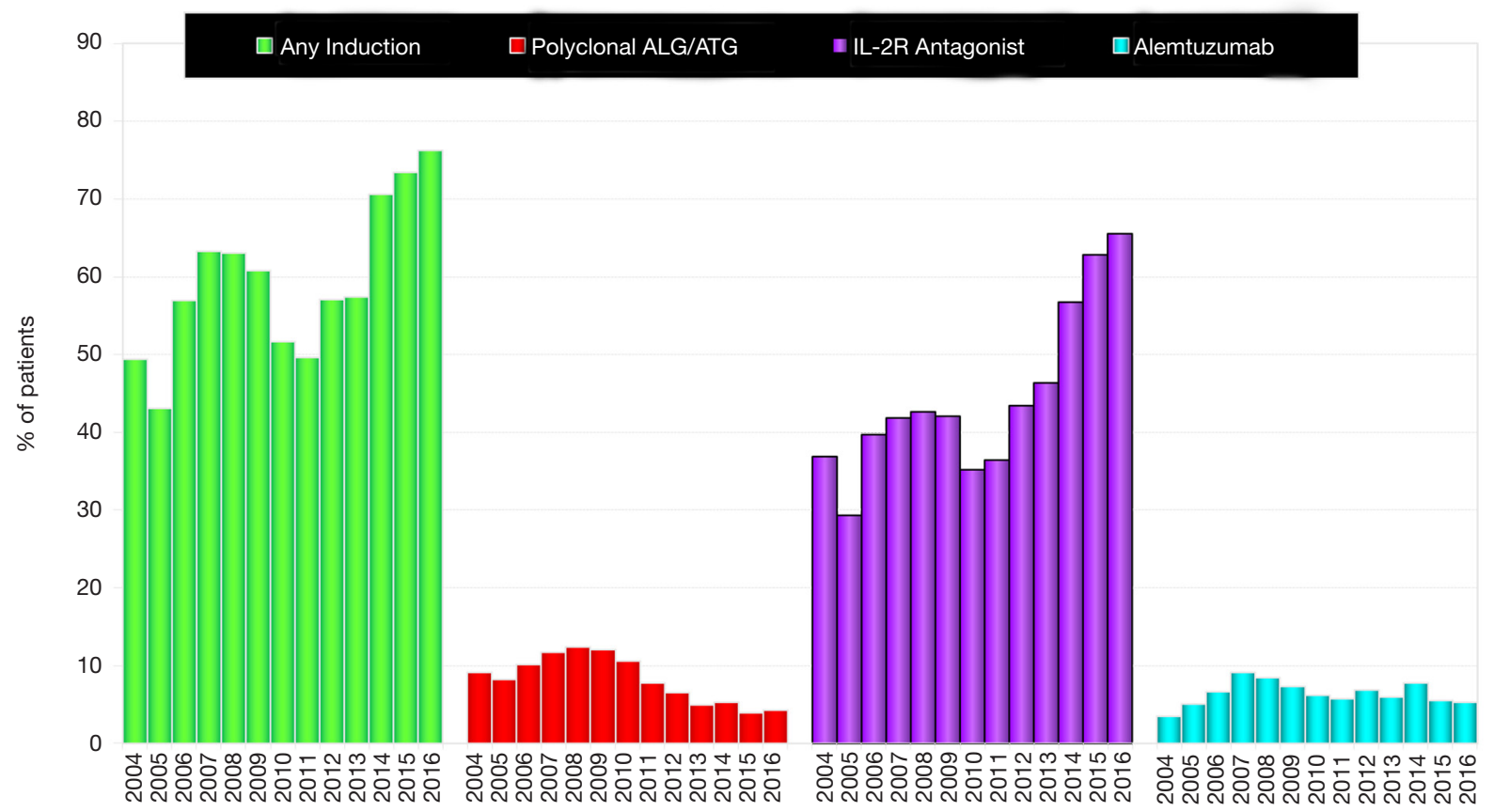

Figure 1 Use of induction immunosuppression as a percentage of all adult lung transplantation reported to the International Society of Heart and Lung Transplantation registry database from January 2004 to December 2016. Included patients were those who were on prednisone and alive at discharge post-lung transplantation. ALG/ATG, anti-lymphocyte globulin/anti-thymocyte globulin; IL-2R, interleukin-2 receptor. Reproduced from (2).

led to improvements in outcomes only in bilateral lung transplant patients when compared to no induction; there were no significant differences in outcomes in single lung transplant recipients receiving ATG versus no induction. More recently, Furuya et al. (17) reviewed 6,117 bilateral lung transplant recipients and found that either the use of alemtuzumab or basiliximab led to longer median survival compared to no induction immunosuppression $(2,321 \mathrm{vs}$. $2,152$ vs. 1,967 days, $\mathrm{P}<0.001)$. Moreover, the development of CLAD at 5 years was significantly lower in patients who received alemtuzumab (22.7\%) versus basiliximab (55.4\%) versus no induction $(55.9 \%)(\mathrm{P}<0.001)$.

The superiority of using one induction agent over another has not been proven, although most (but not all) studies tend to favor basiliximab and alemtuzumab over ATG (22,24-28). A 2013 Cochrane review found no clear benefits or harms when comparing the different induction agents (22). However, this review was based on only six randomized control trials (RCTs) that were at high risk of methodological bias and included a total of 278 patients. Therefore, the authors concluded that future RCTs were needed. Given the equivocal differences in outcomes, the use of basiliximab has increased likely due to the favorable side effect profile that is generally well tolerated by most patients and the possibility, given the above data, that an induction agent could improve long-term outcomes.

ATG and alemtuzumab can cause profound myelosuppression and infusion-related reactions due to cytokine release, which tends to be more severe with ATG. There is also concern that both agents might increase the risk of malignancy based on studies from kidney transplantation, although the data are conflicting $(29,30)$. The allure of alemtuzumab is based on study protocols that have used decreased doses of maintenance immunosuppression $(12,18,20)$. This is especially appealing as it would allow the use of decreased doses of CNI, which are known to be nephrotoxic. However, since 2012, alemtuzumab has been newly marketed for use in multiple sclerosis $\left(\right.$ Lemtrada $\left.^{\circledR}\right)(8)$ and is otherwise available on a limited basis, which may be a reason for its recent decline in use. Although the use of induction agents in lung transplantation has increased, large randomized controlled trials will need to be performed to clearly assess the benefits and harms before induction agents become universal. 


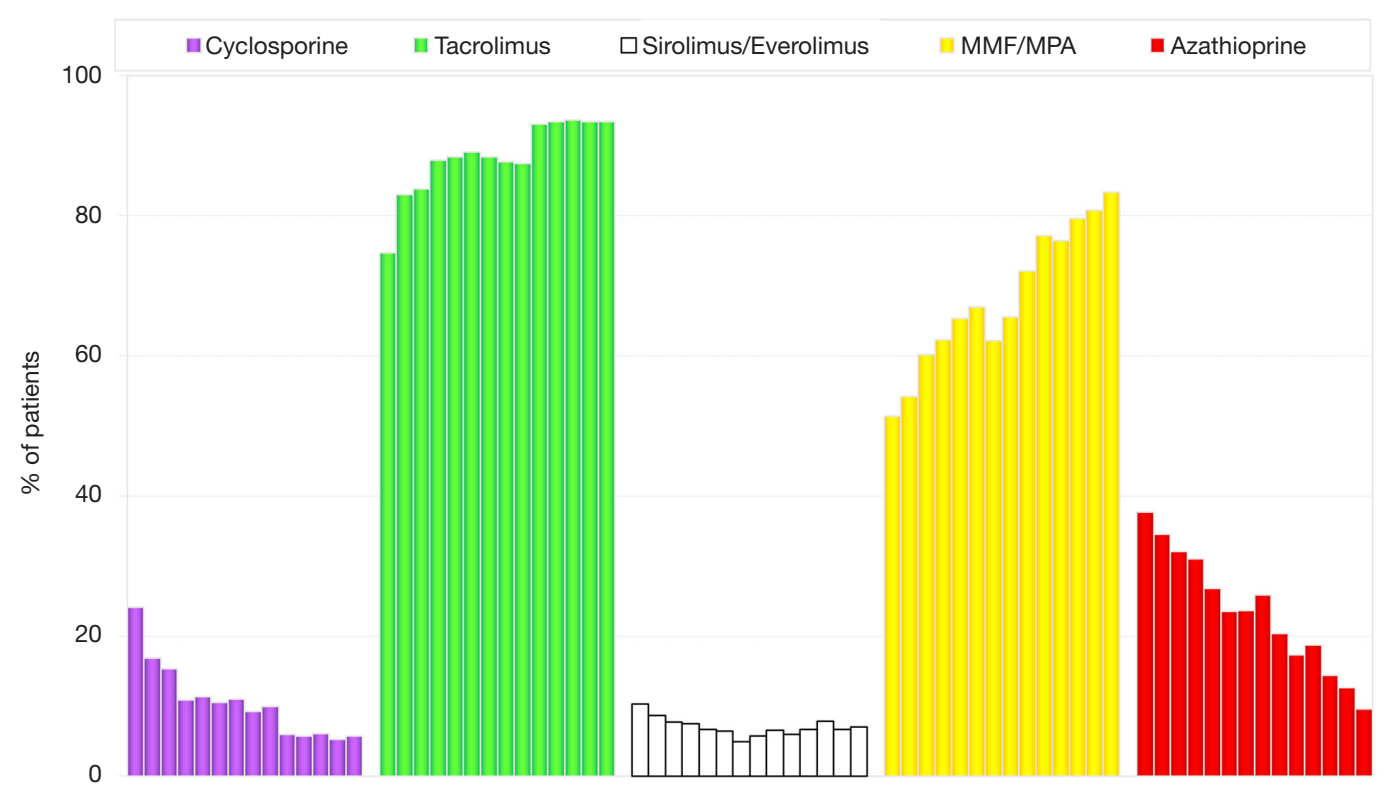

Figure 2 Maintenance immunosuppression as a percentage for all adult lung transplantation at 1-year follow-up reported to the International Society of Heart and Lung Transplantation registry database. Each bar represents the one-year follow up from 2004 to 2017. Included patients were those who were on prednisone and were alive at 1-year follow-up. MMF/MPA, mycophenolate mofetil/mycophenolic acid. Reproduced from (2).

At Loyola, our preference is to use basiliximab for induction immunosuppression. This is based on (I) experience with the agent, (II) tolerability of the medication, (III) evidence of its benefits in reducing acute lung rejection which has been linked to early onset of CLAD (31), and (IV) improved long-term survival as evidenced using the ISHLT registry database (2). The main contraindication to induction therapy is high risk for infection, including cytomegalovirus (CMV) in cases with CMV antibody primary mismatch (positive CMV donor, negative CMV recipient). The first dose of basiliximab is given perioperatively and a second dose is given on post-operative day 4. Overall, until large RCTs are able to clearly assess benefits versus harms of the induction agents and delineate an immunosuppressive regimen, transplant physicians should weight the risk of rejection with the risk of the complications and toxicities associated with the inducting agent in order to improve the long-term outcomes of lung transplantation.

\section{Maintenance immunosuppression}

The purpose of maintenance immunosuppression after lung transplantation is to prevent acute and chronic rejection.
This is delicately balanced by the need to prevent adverse side effects, infectious complications, and the risk of malignancy from the immunosuppressives. Conventional maintenance immunosuppression has been triple drug therapy and most commonly includes a CNI (tacrolimus or cyclosporine), an antiproliferative agent (mycophenolate or azathioprine), and corticosteroids. According to the 2018 International Society for Heart and Lung Transplantation (ISHLT) registry database report, the most commonly used combination at 1-year follow-up is one including tacrolimus, mycophenolate, and corticosteroids (2). The use of cyclosporine and azathioprine has seen a steady decline in the last decade while the introduction of mammalian target of rapamycin (mTOR) inhibitors and a co-simulation blocker have emerged to aid in maintenance immunosuppression for those who do not tolerate a conventional regimen (Figure 2; see also Table 2 for available maintenance immunosuppression agents).

\section{CNIs}

Since FDA approval of cyclosporine in 1983 and then tacrolimus in 1997, CNIs have become the backbone of conventional maintenance immunosuppression although 
Table 2 Maintenance immunosuppression in lung transplantation

\begin{tabular}{|c|c|c|c|}
\hline Agent & Mechanism & Adverse effects & Additional notes \\
\hline $\begin{array}{l}\text { Tacrolimus }[\text { Prograf } \\
\left.\text { Envarsus } \mathrm{XR}^{\circledR}, \text { Astagraf }^{\circledR} \mathrm{XL}^{\circledR}\right] \\
\text { Cyclosporine }\left[\text { Neoral }^{\circledR}(33),\right. \\
\text { Gengraf }^{\circledR}, \text { Sandimmune }\end{array}$ & $\begin{array}{l}\text { Forms a complex that inhibits } \\
\text { the phosphatase activity } \\
\text { of calcineurin, preventing } \\
\text { transcription of cytokines; leads } \\
\text { to decreased activation and } \\
\text { proliferation of T lymphocytes }\end{array}$ & $\begin{array}{l}\text { Nephrotoxicity, neurotoxicity } \\
\text { including posterior reversible } \\
\text { encephalopathy syndrome, } \\
\text { hyperglycemia, hypertension, } \\
\text { hyperlipidemia, hyperkalemia, } \\
\text { tremor }\end{array}$ & $\begin{array}{l}\text { Possible association with } \\
\text { hyperammonemia; see text } \\
\text { regarding aerosolized forms }\end{array}$ \\
\hline \multicolumn{4}{|l|}{ Anti-metabolites } \\
\hline $\begin{array}{l}\text { Mycophenolate mofetil [MMF, } \\
\left.\text { Cellcept }^{\circledR}(34)\right] \text {; Enteric-coated } \\
\text { Mycophenolate sodium [EC- } \\
\left.\text { MPS, Myfortic }{ }^{\circledR}(35)\right]\end{array}$ & $\begin{array}{l}\text { Noncompetitive, reversible } \\
\text { inhibitor of inosine } \\
\text { monophosphate dehydrogenase } \\
\text { which inhibits the de novo } \\
\text { pathway of guanosine nucleotide } \\
\text { synthesis }\end{array}$ & $\begin{array}{l}\text { Gastrointestinal symptoms } \\
\text { including abdominal pain, } \\
\text { nausea, vomiting, diarrhea; } \\
\text { neutropenia, anemia, } \\
\text { thrombocytopenia }\end{array}$ & $\begin{array}{l}\text { Cellcept }^{\circledR} \text { doses and Myfortic } \\
\text { doses are not interchangeable }\end{array}$ \\
\hline Azathioprine $\left[\operatorname{Imuran}^{\circledR}(36)\right]$ & $\begin{array}{l}\text { Metabolized to 6-mercaptourine } \\
\text { which is then incorporated into } \\
\text { DNA and blocks the de novo } \\
\text { and salvage pathways of purine } \\
\text { syntheses }\end{array}$ & $\begin{array}{l}\text { Neutropenia, anemia, } \\
\text { thrombocytopenia, pancreatitis, } \\
\text { hepatotoxicity }\end{array}$ & $\begin{array}{l}\text { Consider genotyping and } \\
\text { phenotyping for TPMT and } \\
\text { NUDT15 as low levels increase } \\
\text { risk for severe myelosuppression }\end{array}$ \\
\hline \multicolumn{4}{|l|}{ mTOR inhibitors } \\
\hline Sirolimus [Rapamune $\left.{ }^{\circledR}(38)\right]$ & $\begin{array}{l}\text { Binds to and forms a complex } \\
\text { with immunophilin FK506-BP12 } \\
\text { that binds mTOR and inhibits } \\
\text { progression of the cell cycle } \\
\text { from G1 to S phase; decreases } \\
\text { activation and proliferation of T } \\
\text { lymphocytes. }\end{array}$ & $\begin{array}{l}\text { Delayed wound healing, } \\
\text { neutropenia, anemia, peripheral } \\
\text { edema, dyslipidemia, TMA/TT/ } \\
\text { HUS, hyperglycemia, stomatitis/ } \\
\text { mouth ulcer, interstitial lung } \\
\text { disease, pneumonitis, venous } \\
\text { thromboembolism }\end{array}$ & $\begin{array}{l}\text { Increased risk for anastomotic } \\
\text { dehiscence if given early post- } \\
\text { transplant }\end{array}$ \\
\hline
\end{tabular}

Brand names are those available in the USA. EBV, Epstein-Barr virus; HUS, hemolytic uremic syndrome; NUDT15, nucleotide diphosphatase; PML, progressive multifocal leukoencephalopathy; PTLD, post-transplant lymphoproliferative disease; TMA, thrombotic microangiopathy; TPMT, thiopurine S-methyltransferase; TTP, thrombotic thrombocytopenic purpura.

neither medication is currently FDA approved specifically for lung transplantation. Cyclosporine binds to intracellular cyclophilin in $\mathrm{T}$ lymphocytes and tacrolimus binds to intracellular FKBP-12, both of which form a complex that inhibit the phosphatase activity of calcineurin, preventing transcription of cytokines such as IL-2, leading to decreased activation and proliferation of $\mathrm{T}$ lymphocytes $(32,33)$. Tacrolimus is more often used in maintenance immunosuppression, as most studies have shown an improvement in incidence of acute rejection and longterm outcomes including a reduced risk for CLAD as compared to cyclosporine (40-44). In one of the largest RCTs comparing tacrolimus to cyclosporine in addition to mycophenolate and corticosteroids, Treede et al. showed that the use of tacrolimus resulted in a lower 3-year cumulative incidence of CLAD compared to cyclosporine 
(11.6\% vs. 21.3\%, $\mathrm{P}=0.037$ ) (45). However, survival between the two groups at 1 - and 3-year was not significantly different. Similarly, a 2013 Cochrane Review which included three RCTs of 413 patients showed that tacrolimus was superior to cyclosporine in incidence of CLAD and lymphocytic bronchitis score but there was no difference in mortality or incidence of acute rejection (46).

While acute and chronic rejection may be improved with tacrolimus, there may be other factors that affect survival including drug-related side effects such as nephrotoxicity. In this regard, new formulations including aerosolized CNIs, mixed formulation regimens including an initial intravenous bolus plus oral CNIs, and extended release CNIs have been reported (47-50). Although these formulations and regimens show promise, larger RCTs will need to clearly show benefit before they are uniformly adopted. Interestingly, the most recent ISHLT registry data set shows both improved 1-year survival and 1-year rejection rate for patients receiving tacrolimus versus cyclosporine (2). Moreover, within several of the studies previously cited, patients were transitioned to tacrolimus from cyclosporine to treat ongoing rejection. For these reasons, tacrolimus is the first-line CNI for maintenance immunosuppression at Loyola. Cyclosporine is mainly used if patients are not able to tolerate tacrolimus.

\section{Anti-metabolites}

Mycophenolate is metabolized to mycophenolic acid, which inhibits inosine-5'-monophosphate dehydrogenase preferentially in $\mathrm{T}$ and $\mathrm{B}$ lymphocytes. This prevents de novo guanosine nucleotide synthesis through depletion of guanosine and deoxyguanosine nucleotides, inhibiting proliferation and activation (51). Azathioprine is a prodrug of 6-mercaptopurine (6-MP), which is converted into several compounds that block both the de novo and salvage pathway syntheses of purine, preventing $\mathrm{T}$ - and B-cell proliferation (52). Caution must be used in patients on xanthine oxidase inhibitors such as allopurinol as xanthine oxidase is responsible for the conversion of 6-MP into its metabolites, possibly leading to profound bone marrow suppression. In addition, patients with low or absent thiopurine or methyltransferase activity are at increased risk of azathioprine associated myelosuppression (53).

Early reports favored mycophenolate over azathioprine in regards to acute rejection $(54,55)$ but subsequent studies have been conflicting, showing similar incidence in acute rejection, survival and CLAD (56-58). Mycophenolate is used more often as it is likely more tolerable to patients.
McNeil et al. found that although acute rejection, CLAD, and survival at 3 years was similar between patients on mycophenolate and azathioprine, more patients discontinued azathioprine (59.6\% vs. $46.5 \%, \mathrm{P}=0.02)$ (57). Moreover, there is evidence that mycophenolate offers benefit in patients with existing CLAD (59) and switching from azathioprine to mycophenolate has been associated with a reduced incidence of cutaneous squamous cell carcinoma (60). There have not been any prospective, randomized trials comparing mycophenolate to azathioprine in patients on tacrolimus. At Loyola, mycophenolate is firstline therapy while azathioprine is used only in patients who do not tolerate mycophenolate.

\section{Corticosteroids}

Corticosteroids suppress multiple inflammatory genes leading to a decrease in $\mathrm{T}$ cell proliferation, decrease in macrophage activation, inhibition of cytokine production and altered lymphocyte migration (61). Corticosteroids are a foundation of maintenance immunosuppression. Although there have been a few reports of successful steroid withdrawal in patients with stable pulmonary function tests after a mean duration of more than 2 years post lung transplantation $(62,63)$, it is currently not recommended to discontinue steroid therapy, and at Loyola we do not completely stop steroid therapy, instead reducing the prednisone dose after 1 year down to $5 \mathrm{mg}$ daily in men and $2.5 \mathrm{mg}$ daily in women.

\section{mTOR inbibitors}

Sirolimus and everolimus bind to intracellular immunophilin FK506-BP12 forming a complex that binds to mTOR, a signaling pathway necessary to promote progression of the cell cycle from G1 to $\mathrm{S}$ phase, thus decreasing activation and proliferation of $\mathrm{T}$ lymphocytes (52). The role of mTOR inhibitors continues to be defined and, both sirolimus and everolimus have been used as an alternative to anti-metabolites $(64,65)$, to decrease CNI doses and therefore, their nephrotoxic effects (66-72), prevention of cancers in those at high-risk, and for the prevention $(73,74)$ and treatment (75-77) of CLAD. However, data on improvement of renal function is equivocal as the early benefits provided by mTOR inhibitors may be lost long-term in lung transplantation $(68,71)$. Moreover, the timing of initiation still needs to be clarified as most studies converted to an mTOR based immunosuppressive 
strategy 3 months to 1 year post transplantation given the catastrophic side effect of decreased wound healing and anastomotic dehiscence $(78,79)$. In addition, mTOR inhibitors have many other adverse effects including increased risk of interstitial lung disease $(71,80,81)$ and venous thromboembolism (82) as well as increased risk for infections and metabolic disorders reported in previous studies, often times leading to discontinuation. Currently, mTOR inhibitors are used in a small percentage of lung transplant patients (2), and at Loyola, are considered months or years after the transplant as a renal-sparing strategy, if skin cancers become prolific or problematic, or if patients are not able to tolerate either of the CNIs or either of the anti-metabolites.

\section{Co-stimulation blocker}

Belatacept inhibits $\mathrm{T}$ cell proliferation and cytokine production by blocking CD28 mediated co-stimulation of T lymphocytes (39). Belatacept has improved graft survival when replacing CNIs in adult kidney transplantation $(83,84)$. However, evidence for its use in lung transplantation is sparse and its role may be as a replacement of CNIs in patients who are intolerant of either tacrolimus or cyclosporine or as a renal-sparing agent $(85,86)$. As with most of the immunosuppressive regimens in lung transplantation, carefully done clinical trials are needed to identify the benefits and timing before its use becomes common. Belatacept is contraindicated in Epstein-Barr virus seronegative patients or in those with unknown status due to the 9-fold increase in post-transplant lymphoproliferative disease found in kidney transplant trials (39).

\section{Adjunctive therapies}

Although not considered immunosuppressive therapy, azithromycin and statins can be used as adjunctive therapy on a case by case basis to improve long term outcomes including as prophylactics against CLAD. Azithromycin is a macrolide antibiotic with anti-inflammatory, immunomodulatory, and pleiotropic effects (87) in addition to its antibacterial activity, and it has been used successfully as a part of maintenance therapy in lung transplant patients with CLAD, providing stabilization or improvement in lung function (88-98). Responders to azithromycin therapy were those with higher bronchoalveolar lavage neutrophil count and interleukin-8 protein levels $(91,92,94)$. Given these results, a study by Vos et al. demonstrated a decrease in CLAD with azithromycin therapy compared to placebo ( $12.5 \%$ vs. $44.2 \%, \mathrm{P}=0.0017$ ) and increased CLAD-free survival (HR 0.27; 95\% CI, 0.092-0.816; $\mathrm{P}=0.020$ ), both 2 years after lung transplantation (99). The beneficial effects of azithromycin were sustained even after reevaluation through post-hoc analysis of the same study after the classification system for CLAD had been updated (100). Azithromycin should be considered in patients with high BAL neutrophilia and/or IL-8 protein levels. Since it is quite well tolerated, some programs initiate azithromycin soon after transplant, even in the absence of such indicators.

Statins are hydroxy-3-methylglutaryl coenzyme A reductase inhibitors used for lowering lipid levels. However, they have other immunomodulatory effects that may improve long-term outcomes after lung transplantation. Johnson et al. compared 39 patients on statins for treatment of hyperlipidemia to 161 control patients not on statin therapy (101). The incidence of biopsy proven acute rejection grade 2 or higher was less in the statin group (15.1\% vs. $25.6 \%, \mathrm{P}<0.01)$. Fifteen patients started on a statin within the post-transplant year one did not develop CLAD whereas $37 \%$ in the control group $\operatorname{did}(\mathrm{P}<0.01)$. Finally, the 6-year survival was greater in the statin group (91\% vs. 54\%, $\mathrm{P}<0.01)$. Similarly, Li et al. used a propensity score analysis comparing 75 lung transplant patients on pravastatin to 340 control patients not on statin therapy (102). Their findings included improvement in survival, maintenance of graft function, and a delay of the onset of CLAD in the pravastatin group. These findings will need to be confirmed with large RCTs, but these studies show promise.

\section{Other considerations}

Throughout the first year post lung transplantation, patients require a plethora of medications in addition to immunosuppressives, especially if there were other preoperative comorbid conditions. That said, the pharmacokinetic and pharmacodynamic properties must be reviewed carefully for each patient, as many of the immunosuppressives (including tacrolimus, cyclosporine, sirolimus, and everolimus) have narrow therapeutic indices that are affected by medications that modulate enzymes of drug metabolism. Frequent therapeutic drug monitoring and a knowledge of the effects of commonly used medications in lung transplantation is necessary to 
help tailor immunosuppressive regimens. This is especially apparent in patients with cystic fibrosis who have increased volumes of distribution, decreased plasma concentration, and enhanced renal and nonrenal elimination of drugs as well as variable gastrointestinal absorption of medications (103). Given these factors and the complexity of drug-drug interactions, the transplant pharmacist plays a vital role as part of the multidisciplinary team and is a key to improving patient outcomes (104).

Closely related to the pharmacokinetics and pharmacodynamics of medications is the field of pharmacogenetics and pharmacogenomics. Simply, pharmacogenetics refers to how single genes and their polymorphisms altar the effect of a drug and pharmacogenomics refers to how the individual's whole genome affects the action of a drug (105), both of which contribute to the interindividual variable response to drug regimens. Within lung transplantation, Burckart et al. has provided an excellent review of specific gene polymorphisms such as CYP3A5 and ABCB1 as well as biomarkers that have had clinical implications (106). As an example, Zheng et al. studied polymorphisms in cytochrome $\mathrm{P} 4503 \mathrm{~A}$ and found that lung transplant recipients who were CYP3A5*1 expressors had an increased tacrolimus dose requirement compared to CYP3A5*3 nonexpressor genotypes (107). As additional gene polymorphisms and biomarkers are discovered, pharmacogenetics and pharmacogenomics hold the promise of drug individualization that is tailored to each specific patient with the hopes of improving their long-term outcomes.

Infection is common in lung transplantation and remains a significant cause of death throughout the lifetime of the recipient (2). Two assays, the ImmuKnow ${ }^{\circledR}$ immune cell function assay and an assay that measures plasma IFN- $\gamma$ have been developed to assess the global immune competence of the immunosuppressed host. Neither test correlates well with immunosuppression drug levels, but there was a correlation between low levels of global immune function and increased infectious risk and high levels correlated with rejection (108-112). However, the data is conflicting regarding the sensitivity of identifying infectious risk and the ImmuKnow ${ }^{\circledR}$ assay has poor specificity. No prospective, randomized trials have been performed utilizing these assays to modify immunosuppression doses. Clinical utility of these assays may be best used to serially monitor patients who have had recurrent infections.

\section{Conclusions}

The number of lung transplants performed continues to increase with improved median survival since the advent of successful lung transplantation in 1983. However, overall survival is impeded by acute rejection, CLAD, infections, and comorbidities, as a result of the adverse effects of immunosuppressive therapy. Transplantation physicians optimize current available therapy to each individual patient but challenges and questions regarding the optimal immunosuppressive strategy remain. Although large randomized trials may help to identify the ideal immunosuppressive regimen for the adult lung transplant population, further research is needed to grow the immunosuppressive armamentarium and develop clinical tools to individualize therapy. Thus, the future direction of immunosuppressive strategies should consider the interindividual variability in response to drug regimens to improve the long-term success of lung transplantation.

\section{Acknowledgments}

Funding: None.

\section{Footnote}

Provenance and Peer Review: This article was commissioned by the Guest Editors (Masaaki Sato and Dong Tian) for the series "Strategies to Achieve Long-Term Success of Lung Transplantation" published in Annals of Translational Medicine. The article was sent for external peer review organized by the Guest Editors and the editorial office.

Conflicts of Interest: The series "Strategies to Achieve LongTerm Success of Lung Transplantation" was commissioned by the editorial office without any funding or sponsorship. The authors have no conflicts of interest to declare.

Ethical Statement: The authors are accountable for all aspects of the work in ensuring that questions related to the accuracy or integrity of any part of the work are appropriately investigated and resolved.

Open Access Statement: This is an Open Access article distributed in accordance with the Creative Commons Attribution-NonCommercial-NoDerivs 4.0 International License (CC BY-NC-ND 4.0), which permits the non- 
commercial replication and distribution of the article with the strict proviso that no changes or edits are made and the original work is properly cited (including links to both the formal publication through the relevant DOI and the license). See: https://creativecommons.org/licenses/by-nc-nd/4.0/.

\section{References}

1. Hardy JD, Webb WR, Dalton ML, et al. Lung Homotransplantation in Man. JAMA 1963;186:1065-74.

2. Chambers DC, Cherikh WS, Goldfarb SB, et al. The International Thoracic Organ Transplant Registry of the International Society for Heart and Lung Transplantation: Thirty-fifth adult lung and heart-lung transplant report-2018; Focus theme: Multiorgan Transplantation. J Heart Lung Transplant 2018;37:1169-83.

3. Verleden GM, Glanville AR, Lease ED, et al. Chronic lung allograft dysfunction: Definition, diagnostic criteria, and approaches to treatment-A consensus report from the Pulmonary Council of the ISHLT. J Heart Lung Transplant 2019;38:493-503.

4. Simulect ${ }^{\circledR}$ [package insert]. East Hanover, NJ: Novartis Pharmaceutical Corporation, 2018.

5. Thymoglobulin ${ }^{\circledR}$ [package insert]. Cambridge, MA: Genzyme Corporation, 2017.

6. Atgam ${ }^{\circledR}$ [package insert]. New York, NY: Pfizer, 2005.

7. Campath ${ }^{\circledR}$ [package insert]. Cambridge, MA: Genzyme, 2009.

8. Lemtrada ${ }^{\circledR}$ [package insert]. Cambridge, MA: Genzyme Corporation, 2017.

9. Palmer SM, Miralles AP, Lawrence CM, et al. Rabbit antithymocyte globulin decreases acute rejection after lung transplantation: results of a randomized, prospective study. Chest 1999;116:127-33.

10. Hachem RR, Edwards LB, Yusen RD, et al. The impact of induction on survival after lung transplantation: an analysis of the International Society for Heart and Lung Transplantation Registry. Clin Transplant 2008;22:603-8.

11. Cai J, Terasaki PI. Induction immunosuppression improves long-term graft and patient outcome in organ transplantation: an analysis of United Network for Organ Sharing registry data. Transplantation 2010;90:1511-5.

12. Shyu S, Dew MA, Pilewski JM, et al. Five-year outcomes with alemtuzumab induction after lung transplantation. J Heart Lung Transplant 2011;30:743-54.

13. Jaksch P, Wiedemann D, Augustin V, et al. Antithymocyte globulin induction therapy improves survival in lung transplantation for cystic fibrosis.
Transpl Int 2013;26:34-41.

14. Whitson BA, Lehman A, Wehr A, et al. To induce or not to induce: a 21 st century evaluation of lung transplant immunosuppression's effect on survival. Clin Transplant 2014;28:450-61.

15. Kirkby S, Whitson BA, Wehr AM, et al. Survival benefit of induction immunosuppression in cystic fibrosis lung transplant recipients. J Cyst Fibros 2015;14:104-10.

16. Duffy JS Jr, Tumin D, Pope-Harman A, et al. Induction Therapy for Lung Transplantation in COPD: Analysis of the UNOS Registry. COPD 2016;13:647-52.

17. Furuya Y, Jayarajan SN, Taghavi S, et al. The Impact of Alemtuzumab and Basiliximab Induction on Patient Survival and Time to Bronchiolitis Obliterans Syndrome in Double Lung Transplantation Recipients. Am J Transplant 2016;16:2334-41.

18. Benazzo A, Schwarz S, Muckenhuber M, et al. Alemtuzumab induction combined with reduced maintenance immunosuppression is associated with improved outcomes after lung transplantation: A single centre experience. PLoS One 2019;14:e0210443.

19. Borro JM, De la Torre M, Miguelez C, et al. Comparative study of basiliximab treatment in lung transplantation. Transplant Proc 2005;37:3996-8.

20. van Loenhout KC, Groves SC, Galazka M, et al. Early outcomes using alemtuzumab induction in lung transplantation. Interact Cardiovasc Thorac Surg 2010;10:190-4.

21. Wehman B, Griffith BP, Balwan A, et al. Long-term outcomes following alemtuzumab induction in lung transplantation. Heart Surg Forum 2013;16:E252-6.

22. Penninga L, Moller CH, Penninga EI, et al. Antibody induction therapy for lung transplant recipients. Cochrane Database Syst Rev 2013;(11):CD008927.

23. Snell GI, Westall GP, Levvey BJ, et al. A randomized, double-blind, placebo-controlled, multicenter study of rabbit ATG in the prophylaxis of acute rejection in lung transplantation. Am J Transplant 2014;14:1191-8.

24. McCurry KR, Iacono A, Zeevi A, et al. Early outcomes in human lung transplantation with Thymoglobulin or Campath-1H for recipient pretreatment followed by posttransplant tacrolimus near-monotherapy. J Thorac Cardiovasc Surg 2005;130:528-37.

25. Hachem RR, Chakinala MM, Yusen RD, et al. A comparison of basiliximab and anti-thymocyte globulin as induction agents after lung transplantation. J Heart Lung Transplant 2005;24:1320-6.

26. Clinckart F, Bulpa P, Jamart J, et al. Basiliximab as 
an alternative to antithymocyte globulin for early immunosuppression in lung transplantation. Transplant Proc 2009;41:607-9.

27. Whited LK, Latran MJ, Hashmi ZA, et al. Evaluation of Alemtuzumab Versus Basiliximab Induction: A Retrospective Cohort Study in Lung Transplant Recipients. Transplantation 2015;99:2190-5.

28. Li KHC, Ho JCS, Recaldin B, et al. Acute Cellular Rejection and Infection Rates in Alemtuzumab vs Traditional Induction Therapy Agents for Lung and Heart Transplantation: A Systematic Review and Meta-analysis. Transplant Proc 2018;50:3723-31.

29. Hall EC, Engels EA, Pfeiffer RM, et al. Association of antibody induction immunosuppression with cancer after kidney transplantation. Transplantation 2015;99:1051-7.

30. Kirk AD, Cherikh WS, Ring M, et al. Dissociation of depletional induction and posttransplant lymphoproliferative disease in kidney recipients treated with alemtuzumab. Am J Transplant 2007;7:2619-25.

31. Mangi AA, Mason DP, Nowicki ER, et al. Predictors of acute rejection after lung transplantation. Ann Thorac Surg 2011;91:1754-62.

32. Prograf $[$ [package insert]. Northbrook, IL: Astellas Pharma US, Inc., 2018.

33. Neoral® [package insert]. East Hanover, NJ: Novartis Pharmaceutical Corporation, 2015.

34. Cellcept® [package insert]. South San Francisco, CA: Genentech USA, Inc., 2019.

35. Myfortic $®$ [package insert]. East Hanover, NJ: Novartis Pharmaceutical Corporation, 2016.

36. Imuran ${ }^{\circledR}$ [package insert]. Roswell, GA: Sebela Pharmaceuticals Inc., 2018.

37. Zortress® [package insert]. East Hanover, NJ: Novartis Pharmaceutical Corporation, 2018.

38. Rapamune® [package insert]. Philadelphia, PA: Wyeth Pharmaceuticals LLC., 2019.

39. Nulojix® [package insert]. Princeton, NJ: Bristol-Myers Squibb Co., 2014.

40. Keenan RJ, Konishi H, Kawai A, et al. Clinical trial of tacrolimus versus cyclosporine in lung transplantation. Ann Thorac Surg 1995;60:580-4.

41. Treede H, Klepetko W, Reichenspurner H, et al. Tacrolimus versus cyclosporine after lung transplantation: a prospective, open, randomized two-center trial comparing two different immunosuppressive protocols. J Heart Lung Transplant 2001;20:511-7.

42. Zuckermann A, Reichenspurner H, Birsan T, et al. Cyclosporine A versus tacrolimus in combination with mycophenolate mofetil and steroids as primary immunosuppression after lung transplantation: one-year results of a 2-center prospective randomized trial. J Thorac Cardiovasc Surg 2003;125:891-900.

43. Hachem RR, Yusen RD, Chakinala MM, et al. A randomized controlled trial of tacrolimus versus cyclosporine after lung transplantation. J Heart Lung Transplant 2007;26:1012-8.

44. Fan Y, Xiao YB, Weng YG. Tacrolimus versus cyclosporine for adult lung transplant recipients: a meta-analysis. Transplant Proc 2009;41:1821-4.

45. Treede H, Glanville AR, Klepetko W, et al. Tacrolimus and cyclosporine have differential effects on the risk of development of bronchiolitis obliterans syndrome: results of a prospective, randomized international trial in lung transplantation. J Heart Lung Transplant 2012;31:797-804.

46. Penninga L, Penninga EI, Moller CH, et al. Tacrolimus versus cyclosporin as primary immunosuppression for lung transplant recipients. Cochrane Database Syst Rev 2013;(5):CD008817.

47. Iacono AT, Johnson BA, Grgurich WF, et al. A randomized trial of inhaled cyclosporine in lung-transplant recipients. N Engl J Med 2006;354:141-50.

48. Hayes D, Zwischenberger JB, Mansour HM. Aerosolized tacrolimus: a case report in a lung transplant recipient. Transplant Proc 2010;42:3876-9.

49. Snell GI, Ivulich S, Mitchell L, et al. Evolution to twice daily bolus intravenous tacrolimus: optimizing efficacy and safety of calcineurin inhibitor delivery early post lung transplant. Ann Transplant 2013;18:399-407.

50. Patel N, Cook A, Greenhalgh E, et al. Overview of extended release tacrolimus in solid organ transplantation. World J Transplant 2016;6:144-54.

51. Allison AC, Eugui EM. Mechanisms of action of mycophenolate mofetil in preventing acute and chronic allograft rejection. Transplantation 2005;80:S181.

52. Taylor AL, Watson CJ, Bradley JA. Immunosuppressive agents in solid organ transplantation: Mechanisms of action and therapeutic efficacy. Crit Rev Oncol Hematol 2005;56:23-46.

53. Relling MV, Gardner EE, Sandborn WJ, et al. Clinical pharmacogenetics implementation consortium guidelines for thiopurine methyltransferase genotype and thiopurine dosing: 2013 update. Clin Pharmacol Ther 2013;93:324-5.

54. Ross DJ, Waters PF, Levine M, et al. Mycophenolate mofetil versus azathioprine immunosuppressive regimens after lung transplantation: preliminary experience. J Heart 
Lung Transplant 1998;17:768-74.

55. Zuckermann A, Klepetko W, Birsan T, et al. Comparison between mycophenolate mofetil- and azathioprine-based immunosuppressions in clinical lung transplantation. J Heart Lung Transplant 1999;18:432-40.

56. Palmer SM, Baz MA, Sanders L, et al. Results of a randomized, prospective, multicenter trial of mycophenolate mofetil versus azathioprine in the prevention of acute lung allograft rejection. Transplantation 2001;71:1772-6.

57. McNeil K, Glanville AR, Wahlers T, et al. Comparison of mycophenolate mofetil and azathioprine for prevention of bronchiolitis obliterans syndrome in de novo lung transplant recipients. Transplantation 2006;81:998-1003.

58. Speich R, Schneider S, Hofer M, et al. Mycophenolate mofetil reduces alveolar inflammation, acute rejection and graft loss due to bronchiolitis obliterans syndrome after lung transplantation. Pulm Pharmacol Ther 2010;23:445-9.

59. Whyte RI, Rossi SJ, Mulligan MS, et al. Mycophenolate mofetil for obliterative bronchiolitis syndrome after lung transplantation. Ann Thorac Surg 1997;64:945-8.

60. Vos M, Plasmeijer EI, van Bemmel BC, et al. Azathioprine to mycophenolate mofetil transition and risk of squamous cell carcinoma after lung transplantation. J Heart Lung Transplant 2018;37:853-9.

61. Barnes PJ. How corticosteroids control inflammation: Quintiles Prize Lecture 2005. Br J Pharmacol 2006; 148:245-54.

62. Borro JM, Sole A, De la Torre M, et al. Steroid withdrawal in lung transplant recipients. Transplant Proc 2005;37:3991-3.

63. Shitrit D, Bendayan D, Sulkes J, et al. Successful steroid withdrawal in lung transplant recipients: result of a pilot study. Respir Med 2005;99:596-601.

64. Snell GI, Valentine VG, Vitulo P, et al. Everolimus versus azathioprine in maintenance lung transplant recipients: an international, randomized, double-blind clinical trial. Am J Transplant 2006;6:169-77.

65. Bhorade S, Ahya VN, Baz MA, et al. Comparison of sirolimus with azathioprine in a tacrolimus-based immunosuppressive regimen in lung transplantation. Am J Respir Crit Care Med 2011;183:379-87.

66. Shitrit D, Rahamimov R, Gidon S, et al. Use of sirolimus and low-dose calcineurin inhibitor in lung transplant recipients with renal impairment: results of a controlled pilot study. Kidney Int 2005;67:1471-5.

67. Gullestad L, Iversen M, Mortensen SA, et al. Everolimus with reduced calcineurin inhibitor in thoracic transplant recipients with renal dysfunction: a multicenter, randomized trial. Transplantation 2010;89:864-72.

68. Roman A, Ussetti P, Zurbano F, et al. A retrospective 12-month study of conversion to everolimus in lung transplant recipients. Transplant Proc 2011;43:2693-8.

69. Parada MT, Alba A, Sepulveda C, et al. Long-term use of everolimus in lung transplant patients. Transplant Proc 2011;43:2313-5.

70. Peddi VR, Wiseman A, Chavin K, et al. Review of combination therapy with mTOR inhibitors and tacrolimus minimization after transplantation. Transplant Rev (Orlando) 2013;27:97-107.

71. Gullestad L, Eiskjaer H, Gustafsson F, et al. Long-term outcomes of thoracic transplant recipients following conversion to everolimus with reduced calcineurin inhibitor in a multicenter, open-label, randomized trial. Transpl Int 2016;29:819-29.

72. Gottlieb J, Neurohr C, Muller-Quernheim J, et al. A randomized trial of everolimus-based quadruple therapy vs standard triple therapy early after lung transplantation. Am J Transplant 2019;19:1759-69.

73. Sacher VY, Fertel D, Srivastava K, et al. Effects of prophylactic use of sirolimus on bronchiolitis obliterans syndrome development in lung transplant recipients. Ann Thorac Surg 2014;97:268-74.

74. Glanville AR, Aboyoun C, Klepetko W, et al. Threeyear results of an investigator-driven multicenter, international, randomized open-label de novo trial to prevent BOS after lung transplantation. J Heart Lung Transplant 2015;34:16-25.

75. Cahill BC, Somerville KT, Crompton JA, et al. Early experience with sirolimus in lung transplant recipients with chronic allograft rejection. J Heart Lung Transplant 2003;22:169-76.

76. Villanueva J, Boukhamseen A, Bhorade SM. Successful use in lung transplantation of an immunosuppressive regimen aimed at reducing target blood levels of sirolimus and tacrolimus. J Heart Lung Transplant 2005;24:421-5.

77. Hernández RL, Gil PU, Gallo CG, et al. Rapamycin in lung transplantation. Transplant Proc 2005;37:3999-4000.

78. King-Biggs MB, Dunitz JM, Park SJ, et al. Airway anastomotic dehiscence associated with use of sirolimus immediately after lung transplantation. Transplantation 2003;75:1437-43.

79. Groetzner J, Kur F, Spelsberg F, et al. Airway anastomosis complications in de novo lung transplantation with sirolimus-based immunosuppression. J Heart Lung 
Transplant 2004;23:632-8.

80. Garrean S, Massad MG, Tshibaka M, et al. Sirolimusassociated interstitial pneumonitis in solid organ transplant recipients. Clin Transplant 2005;19:698-703.

81. Lopez P, Kohler S, Dimri S. Interstitial Lung Disease Associated with mTOR Inhibitors in Solid Organ Transplant Recipients: Results from a Large Phase III Clinical Trial Program of Everolimus and Review of the Literature. J Transplant 2014;2014:305931.

82. Ahya VN, McShane PJ, Baz MA, et al. Increased risk of venous thromboembolism with a sirolimus-based immunosuppression regimen in lung transplantation. J Heart Lung Transplant 2011;30:175-81.

83. Vincenti F, Charpentier B, Vanrenterghem Y, et al. A phase III study of belatacept-based immunosuppression regimens versus cyclosporine in renal transplant recipients (BENEFIT study). Am J Transplant 2010;10:535-46.

84. Vincenti F, Larsen CP, Alberu J, et al. Three-year outcomes from BENEFIT, a randomized, activecontrolled, parallel-group study in adult kidney transplant recipients. Am J Transplant 2012;12:210-7.

85. Timofte I, Terrin M, Barr E, et al. Belatacept for renal rescue in lung transplant patients. Transpl Int 2016;29:453-63.

86. Iasella CJ, Winstead RJ, Moore CA, et al. Maintenance Belatacept-Based Immunosuppression in Lung Transplantation Recipients Who Failed Calcineurin Inhibitors. Transplantation 2018;102:171-7.

87. Vos R, Vanaudenaerde BM, Verleden SE, et al. Antiinflammatory and immunomodulatory properties of azithromycin involved in treatment and prevention of chronic lung allograft rejection. Transplantation 2012;94:101-9.

88. Verleden GM, Dupont LJ. Azithromycin therapy for patients with bronchiolitis obliterans syndrome after lung transplantation. Transplantation 2004;77:1465-7.

89. Yates B, Murphy DM, Forrest IA, et al. Azithromycin reverses airflow obstruction in established bronchiolitis obliterans syndrome. Am J Respir Crit Care Med 2005;172:772-5.

90. Shitrit D, Bendayan D, Gidon S, et al. Long-term azithromycin use for treatment of bronchiolitis obliterans syndrome in lung transplant recipients. J Heart Lung Transplant 2005;24:1440-3.

91. Verleden GM, Vanaudenaerde BM, Dupont LJ, et al. Azithromycin reduces airway neutrophilia and interleukin-8 in patients with bronchiolitis obliterans syndrome. Am J Respir Crit Care Med 2006;174:566-70.
92. Gottlieb J, Szangolies J, Koehnlein T, et al. Long-term azithromycin for bronchiolitis obliterans syndrome after lung transplantation. Transplantation 2008;85:36-41.

93. Porhownik NR, Batobara W, Kepron W, et al. Effect of maintenance azithromycin on established bronchiolitis obliterans syndrome in lung transplant patients. Can Respir J 2008;15:199-202.

94. Vos R, Vanaudenaerde BM, Ottevaere A, et al. Longterm azithromycin therapy for bronchiolitis obliterans syndrome: divide and conquer? J Heart Lung Transplant 2010;29:1358-68.

95. Jain R, Hachem RR, Morrell MR, et al. Azithromycin is associated with increased survival in lung transplant recipients with bronchiolitis obliterans syndrome. J Heart Lung Transplant 2010;29:531-7.

96. Federica M, Nadia S, Monica M, et al. Clinical and immunological evaluation of 12-month azithromycin therapy in chronic lung allograft rejection. Clin Transplant 2011;25:E381.

97. Kingah PL, Muma G, Soubani A. Azithromycin improves lung function in patients with post-lung transplant bronchiolitis obliterans syndrome: a meta-analysis. Clin Transplant 2014;28:906-10.

98. Corris PA, Ryan VA, Small T, et al. A randomised controlled trial of azithromycin therapy in bronchiolitis obliterans syndrome (BOS) post lung transplantation. Thorax 2015;70:442-50.

99. Vos R, Vanaudenaerde BM, Verleden SE, et al. A randomised controlled trial of azithromycin to prevent chronic rejection after lung transplantation. Eur Respir J 2011;37:164-72.

100. Ruttens D, Verleden SE, Vandermeulen E, et al. Prophylactic Azithromycin Therapy After Lung Transplantation: Post hoc Analysis of a Randomized Controlled Trial. Am J Transplant 2016;16:254-61.

101.Johnson BA, Iacono AT, Zeevi A, et al. Statin use is associated with improved function and survival of lung allografts. Am J Respir Crit Care Med 2003;167:1271-8.

102. Li Y, Gottlieb J, Ma D, et al. Graft-protective effects of the HMG-CoA reductase inhibitor pravastatin after lung transplantation---a propensity score analysis with 23 years of follow-up. Transplantation 2011;92:486-92.

103. Prandota J. Clinical pharmacology of antibiotics and other drugs in cystic fibrosis. Drugs 1988;35:542-78.

104. Sam S, Guerin A, Rieutord A, et al. Roles and Impacts of the Transplant Pharmacist: A Systematic Review. Can J Hosp Pharm 2018;71:324-37.

105. Wavamunno MD, Chapman JR. Individualization of 
immunosuppression: concepts and rationale. Curr Opin Organ Transplant 2008;13:604-8.

106. Burckart GJ, Hutchinson IV, Zeevi A. Pharmacogenomics and lung transplantation: clinical implications. Pharmacogenomics J 2006;6:301-10.

107.Zheng H, Zeevi A, Schuetz E, et al. Tacrolimus dosing in adult lung transplant patients is related to cytochrome P4503A5 gene polymorphism. J Clin Pharmacol 2004;44:135-40.

108. Bhorade SM, Janata K, Vigneswaran WT, et al. Cylex ImmuKnow assay levels are lower in lung transplant recipients with infection. J Heart Lung Transplant 2008;27:990-4.

109. Husain S, Raza K, Pilewski JM, et al. Experience with

Cite this article as: Chung PA, Dilling DF. Immunosuppressive strategies in lung transplantation. Ann Transl Med 2020;8(6):409. doi: 10.21037/atm.2019.12.117 immune monitoring in lung transplant recipients: correlation of low immune function with infection. Transplantation 2009;87:1852-7.

110. Shino MY, Weigt SS, Saggar R, et al. Usefulness of immune monitoring in lung transplantation using adenosine triphosphate production in activated lymphocytes. J Heart Lung Transplant 2012;31:996-1002.

111.Piloni D, Magni S, Oggionni T, et al. Clinical utility of CD4+ function assessment (ViraCor-IBT ImmuKnow test) in lung recipients. Transpl Immunol 2016;37:35-9.

112.Mian M, Natori Y, Ferreira V, et al. Evaluation of a Novel Global Immunity Assay to Predict Infection in Organ Transplant Recipients. Clin Infect Dis 2018;66:1392-7. 